\title{
Remoção de Dibenzotiofeno através da adsorção por Modificação da Superfície da Sílica com N-metil-imidazólio com ânions $\mathbf{N}\left(\mathbf{T f}_{2}\right)^{-}$
}

\author{
A. S. Carvalho ${ }^{1}$; J. F. Conto ${ }^{1}$; K. V. Campos ${ }^{1}$; M. R. Oliveira ${ }^{1}$; T. G. Brandão ${ }^{1}$; S. M. S. \\ Egues $^{1}$
}

${ }^{1}$ Instituto de Pesquisa e Tecnologia-ITP, PEP - Universidade Tiradentes, Av. Murilo Dantas, 300 - CEP: 49030-230 - Aracaju - SE, Brasil.

E-mail para contato: aialasc@hotmail.com

\begin{abstract}
RESUMO - Diante dos problemas causados pelos compostos sulfurados nas refinarias, nos motores de automóveis e ao meio ambiente, os órgãos de controle ambiental (Conama) estabeleceram novos regulamentos para reduzir o teor de enxofre nos combustíveis. Este trabalho desenvolveu um novo material adsorvente, agregando compostos orgânicos ionizados (líquido iônico, LI) em um adsorvente sólido (sílica) para remoção de dibenzotiofeno presentes no petróleo. O dibenzotiofeno foi seletivamente removido por adsorção utilizando $\mathrm{N}$ - metil - imidazólio com $\mathrm{N}\left(\mathrm{Tf}_{2}\right)^{-}$ suportados em sílica. A síntese do material foi feita por impregnação do cátion e do ânion do líquido iônico através do método convencional (banho de óleo). As amostras foram caracterizadas por técnicas clássicas de caracterização de materiais sólidos: adsorção e dessorção de $\mathrm{N}_{2}$ (métodos BET e BJH), titulação de cloretos, CHN, espectroscopia no infravermelho com transformada de Fourier (FTIR) e analises cromatográficas por GC-FID. Através do estudo de equilíbrio e modelagem cinética de adsorção foi possível comprovar a eficiência do adsorvente Sil-IMI-N $\left(\mathrm{Tf}_{2}\right)^{-}$para adsorção do dibenzotiofeno.
\end{abstract}

\section{INTRODUÇÃO}

Os compostos sulfurados se apresentam em maior número entre as resinas e os asfaltenos, que são moléculas grandes, com alta relação carbono/hidrogênio e marcante presença de enxofre, oxigênio e nitrogênio (de 6,9 a 7,3\%). (Thomas et al., 2004). Diante da importância dada atualmente aos compostos sulfurados foi ressaltado os problemas causados pelos compostos sulfurados. Dentre estes está o meio ambiente, onde os órgãos de controle ambiental (Conama) estabeleceram novos regulamentos para reduzir o teor de enxofre nos combustíveis, quer seja diesel, gasolina, álcool, biodiesel e gás natural. Problemas também observados no setor petrolífero, em seus produtos e linhas de processos, vêm motivando o setor para mudanças nos seus processos de tratamento. Por meio de pesquisas, o mercado já disponibiliza um diesel mais limpo de enxofre o S-10 lançado pela Petrobras atualmente, significando $10 \mathrm{ppm}$ de enxofre no diesel.

Vários estudos têm focado na remoção de compostos sulfurados de petróleo por métodos alternativos tais como a biodessulfurização, dessulfurização por adsorção, dessulfurização por ultrassom, adsorção, adsorção oxidativa e extração líquido-líquido. Todos 
estes são complementares ao processo de hidrotratamento, que utiliza grandes quantidades de hidrogênio, temperaturas elevadas $\left(>300^{\circ} \mathrm{C}\right)$, altas pressões $(>4 \mathrm{MPa})$ e catalisadores sofisticados de cobalto e molibdênio, resultando em processo de alto custo. Dentre estes métodos alternativos, a adsorção mostra-se um processo interessante com o intuito de realizar uma remoção profunda dos sulfurados (Irvine, 1998; Marín-rosas et al. 2010).

\section{METODOLOGIA}

\subsection{Preparo da Sílica Funcionalizada com Liquido Iônico}

Para promover a remoção de impurezas e a ativação da sílica (Macherey-Nagel), esta foi lavada três vezes com Acetona P.A (Vetec) no ultrassom. Posteriormente foi levada à estufa a $110^{\circ} \mathrm{C}$ por 12 horas para eliminação da água fisicamente adsorvida e foi armazenada em dessecador sob vácuo.

Com o intuito de promover a maior cobertura possível da superfície, utilizou-se um excesso do ligante silano 3-cloropropiltrimetoxisilano (CPTMS da Sigma-Aldrich), uma massa de $0,53 \mathrm{~g}\left(2,67 \times 10^{-3} \mathrm{~mol}\right)$. Dessa forma, $20 \mathrm{~g}$ de sílica foram adicionadas a uma solução contendo 10,6g de CPTMS em $200 \mathrm{~mL}$ de tolueno. A suspensão foi aquecida a $80^{\circ} \mathrm{C}$ e mantida sob refluxo do solvente durante 24 horas. A sílica modificada foi lavada com $100 \mathrm{~mL}$ de tolueno, $80 \mathrm{~mL}$ de etanol e por fim $50 \mathrm{~mL}$ de éter etílico (todos Vetec) para auxiliar na secagem. O material assim obtido será chamado de sílica-CPTMS.

A sílica inicialmente impregnada com o agente ligante silano 3cloropropiltrimetoxisilano foi posta a reagir com 3,28g do 1-n-metil-imidazólio (SigmaAldrich, $\mathrm{M}=82 \mathrm{~g} \cdot \mathrm{mol}^{-1}$; $\mathrm{d}=1,035 \mathrm{~g} \cdot \mathrm{mL}^{-1}$ ) em um balão de vidro sob refluxo, aquecido a $110^{\circ} \mathrm{C}$ com banho de óleo durante 24 horas, conforme ilustrado na Figura 1. O produto da reação foi recuperado por filtração e lavado com tolueno, etanol e éter etílico, seguido de lavagem por método Soxhlet para remoção de compostos orgânicos em excesso. Posteriormente foi feita a secagem em estufa a $80^{\circ} \mathrm{C}$ por $8 \mathrm{~h}$ e armazenagem sob vácuo em dessecador. O material assim obtido será chamado de Sílica-IMI $\mathrm{Cl}^{-}$.

A troca do ânion de compensação $\mathrm{Cl}^{-}$do anel imidazólio pelo ânion bis (trifluorometano-sufonilmida), $\mathrm{N}\left(\mathrm{Tf}_{2}\right)^{-}$. Foram adicionados $5 \mathrm{~g}$ da Sílica-IMI em uma solução contendo $2 \mathrm{mmol}$ do sal de lítio bis (trifluorometano-sufonilmida) (Sigma-Aldrich, $\mathrm{M}=287,1$ g. $\mathrm{mol}^{-1}$ ) em $20 \mathrm{~mL}$ de água ultrapura. A suspensão formada foi agitada por 24 horas a temperatura ambiente. O sólido foi recuperado por filtração a vácuo e lavado com $200 \mathrm{~mL}$ de água ultrapura, sendo então posto na estufa a $80^{\circ} \mathrm{C}$ por 8 horas. $\mathrm{O}$ esquema reacional está apresentado na Figura 1. O material assim obtido será chamado de Síl-IMI-N $\left(\mathrm{Tf}_{2}\right)^{-}$. 


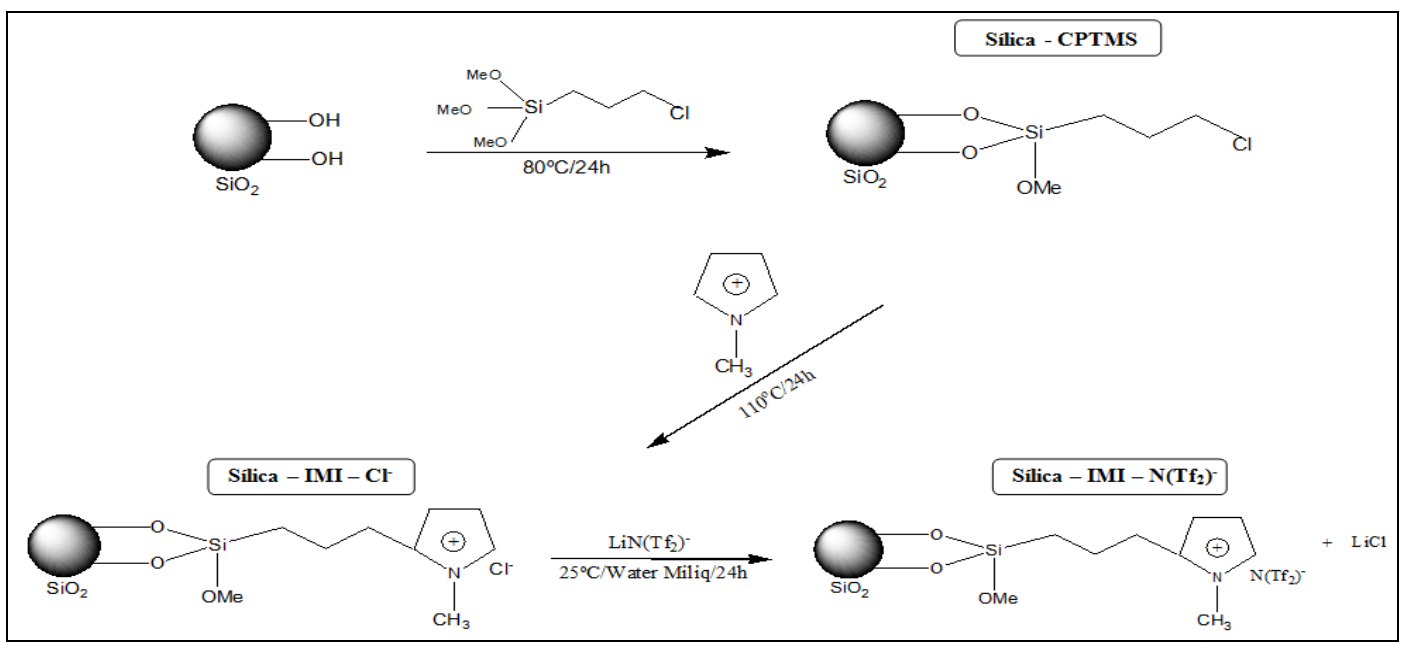

Figura 1 - Via de Síntese do Sílica-IMI-N( $\left(\mathrm{Tf}_{2}\right)^{-}$.

\subsection{Caracterizações da Sílica Funcionalizada com Líquido Iônico}

Para confirmação da troca do ânion $\mathrm{Cl}^{-}$pelo bis(trifluorometano-sufonilmida) $\mathrm{N}\left(\mathrm{Tf}_{2}\right)^{-}$, foi feita análise de cloreto livre por titulação potenciométrica com $\mathrm{AgNO}_{3}$. O íon nitrato desloca o íon cloreto ligado ao anel imidazólio, formando $\mathrm{HCl}$ em solução. Faz-se então a determinação da quantidade de cloreto na solução por titulação potenciométrica com uma solução de nitrato de prata $\left(\mathrm{AgNO}_{3}\right)$ até precipitação do $\mathrm{AgCl}$. Não havendo precipitação do $\mathrm{AgCl}$ no final da titulação, evidenciava-se que ocorreu a troca dos ânions. Tomou-se 0,150 mg da amostra de sílica funcionalizada e adicionou-se a $40 \mathrm{~mL}$ de uma solução de ácido nítrico $0,1 \mathrm{~mol} \mathrm{~L}^{-1}$. Esta suspensão foi agitada por $30 \mathrm{~min}$ a temperatura ambiente. Tomou-se uma alíquota de $10 \mathrm{~mL}$ e titulou-se com solução de $\mathrm{AgNO}_{3}$ 0,1 mol/L, utilizando um eletrodo de prata como indicador.

A área superficial específica $\left(S_{\text {B.E.T. }}\right)$ e a distribuição do volume de poro foram determinadas através das adsorção/dessorção de $\mathrm{N}_{2} \mathrm{a}-196{ }^{\circ} \mathrm{C}$, no equipamento Autosorb I Quantachrome Instruments, utilizando o método BET e modelo BJH (multipontos), respectivamente. As amostras foram pré-tratadas a vácuo $2,0 \times 10^{-3} \mathrm{~Pa}$ a temperatura de $120{ }^{\circ} \mathrm{C}$ por 12 horas, para remover a umidade e impurezas. A análise de $\mathrm{CHN}$, para a determinação dos teores de carbono, hidrogênio e nitrogênio, foi realizada em Analisador Perkin-Elmer, modelo PE 2400. As análises foram feitas em triplicata. Na análise de infravermelho foi utilizado um espectrofotômetro com transformada de Fourier Perkin Elmer 1600 FTIR, na região de 4000 a $400 \mathrm{~cm}^{-1}$, com resolução de $2 \mathrm{~cm}^{-1}$ e 64 acumulações. Utilizaram-se pastilhas preparadas a partir da dispersão dos sólidos em $\mathrm{KBr}$, na proporção de 1:100 e as análises foram feitas em temperatura ambiente.

\subsection{Cinética de Adsorção}

Os experimentos de adsorção foram realizados em modo batelada utilizando uma incubadora refrigerada (MA-830A Marconi). A cinética de adsorção do dibenzotiofeno foi determinada utilizando $300 \mathrm{mg}$ de adsorvente em $10 \mathrm{~mL}$ de hexano (Aldrich) em frascos de 
$15 \mathrm{~mL}$ fechados, contendo diferentes concentrações de dibenzotiofeno de 25,50 e $100 \mathrm{ppm}$ a $40{ }^{\circ} \mathrm{C}$. Alíquotas de $1 \mathrm{~mL}$ foram retiradas em tempos pré-estabelecidos $(0,15,30,45,60,90$, $120,180,240,300 \mathrm{~min}$ ) para posterior análise cromatográfica.

A avaliação quantitativa dos dados para a capacidade de adsorção do adsorvente Sil$\mathrm{IMI}-\mathrm{N}\left(\mathrm{Tf}_{2}\right)^{-}$foi feita através das isotermas de adsorção conforme a equação (1).

$$
\log \left(q_{e}-q\right)=\log q_{e} \frac{K_{1}}{2.303} t
$$

Onde

$\mathrm{C}_{0}$ e $\mathrm{C}_{\mathrm{t}}(\mathrm{mg} / \mathrm{L})$ são as concentrações da fase líquida da solução de dibenzotiofeno inicial e t é tempo, respectivamente;

V - é o volume da solução em (L);

$\mathrm{W}$ - é a massa do adsorvente (g).

A percentagem de remoção de dibenzotiofeno foi obtida pela equação (2).

$$
(\%)=\frac{\left(C_{0}-C_{t}\right)}{c_{0}} \cdot 100
$$

\section{RESULTADOS E DISCUSSÃO}

\subsection{Caracterização da Sílica Funcionalizada com Líquido Iônico}

Os materiais apresentaram perfis similares de adsorção de $\mathrm{N}_{2}$ característicos de isoterma tipo IV, com duas regiões distintas: uma a baixas pressões relativas $\left(\mathrm{P} / \mathrm{P}_{0}<0,2-0,3\right)$ correspondente à adsorção de $\mathrm{N}_{2}$ na monocamada; na segunda região $\left(\mathrm{P} / \mathrm{P}_{0}=0,5-1,0\right)$ ocorre a condensação capilar característica de materiais mesoporosos Lowell e Shields (1979). Todas as curvas de dessorção apresentaram histerese do tipo $\mathrm{H} 2$ relacionada a poros cilindros abertos nas duas extremidades definida (Gregg e Sing, 1982; Storck, et al. 1998). Quanto à distribuição de volume de poros, pode-se observar que as amostras mostraram distribuições semelhantes, com diâmetro médio de poro em torno de 4-5 nm. A Tabela 1 apresenta os valores obtidos na análise textural da sílica pura e funcionalizada.

Tabela 1. Análise textural da sílica pura e funcionalizada

\begin{tabular}{lccc}
\hline \multicolumn{1}{c}{ Amostra } & $\begin{array}{c}\text { Área BET } \\
\left(\mathrm{m}^{2} / \mathrm{g}\right)\end{array}$ & $\begin{array}{c}\text { Volume de poros } \\
\left(\mathrm{cm}^{3} / \mathrm{g}\right)\end{array}$ & $\begin{array}{c}\text { Diâmetro } \\
(\mathrm{nm})\end{array}$ \\
\hline Sílica Pura & 482 & 0,76 & 4,68 \\
Sil- $I M I$ & 349 & 0,50 & 4,35 \\
Sil-IMI-N $\left(T f_{2}\right)^{-}$ & 294 & 0,38 & 4,01 \\
\hline
\end{tabular}


Observa-se na Figura 2 que a funcionalização com o líquido iônico diminuiu progressivamente a área da sílica, o seu volume e diâmetro de poros. Entretanto, o efeito da funcionalização foi mais importante para a área superficial (redução de 40 \%) e volume de poros (redução de 50\%), afetando pouco o diâmetro de poro.
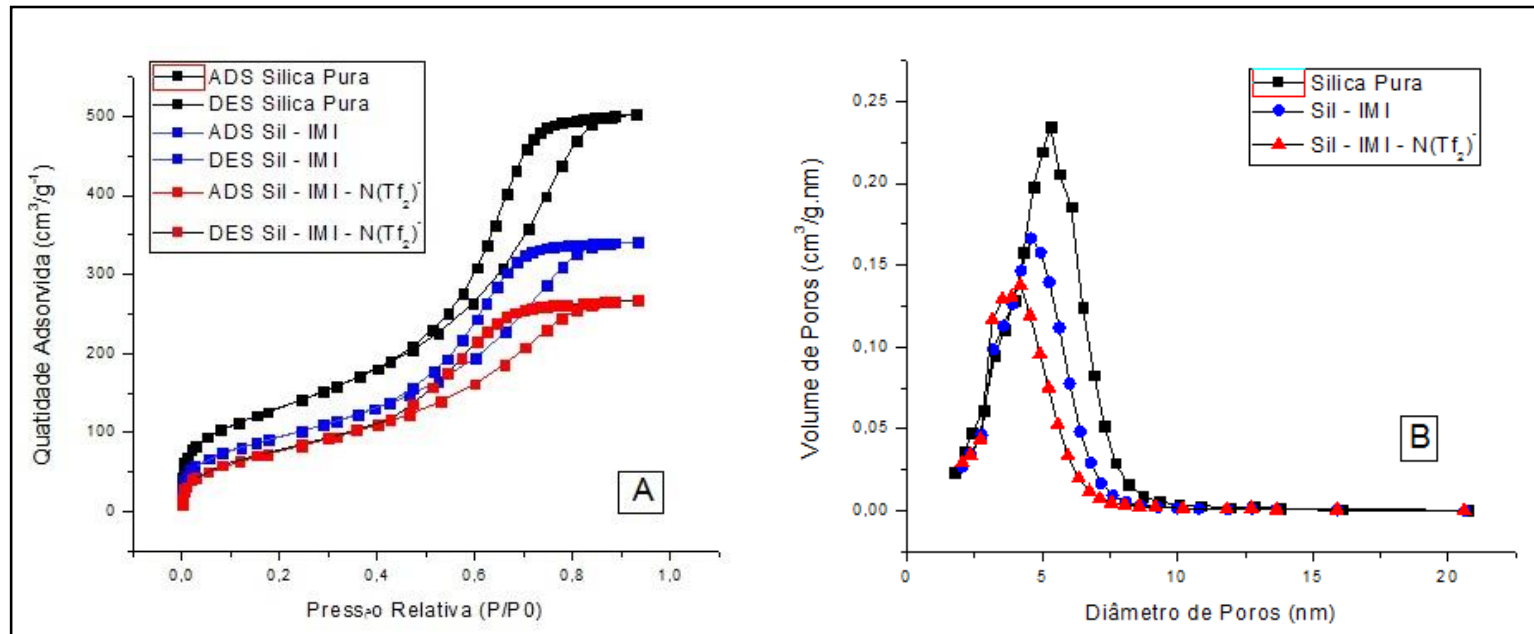

Figura 2 - (A) Isoterma de adsorção/dessorção $\mathrm{N}_{2}$ e (B) distribuição do tamanho de poro da Sílica pura, Sil-IMI e Sil-IMI-N $\left(\mathrm{Tf}_{2}\right)^{-}$.

\subsection{Análise Elementar (CHN)}

Os resultados da análise elementar por CHN, mostrados na Tabela 2, indicam que a funcionalização da Sílica-IMI ocorreu a contento, pois observa-se um teor de carbono muito superior $\left(6,02 \mathrm{mmol} \mathrm{g}^{-1}\right)$ ao encontrado na sílica pura, $(0,07 \mathrm{mmol} / \mathrm{g})$. Após a adição do grupo orgânico $\mathrm{N}\left(\mathrm{Tf}_{2}\right)^{-}$observou-se um pequeno aumento no teor deste elemento para $6,79 \mathrm{mmol} \mathrm{\textrm {g } ^ { - }}$ 1, o que nos permite dizer que ocorreu o ancoramento do ânion bis (trifluorometanosufonilmida) na sílica.

Tabela 2 - Análise Elementar

\begin{tabular}{lcccc}
\hline \multicolumn{1}{c}{ Amostra } & \multicolumn{3}{c}{ Análise Elementar } & Análise de \\
\cline { 2 - 4 } & $\begin{array}{c}\text { Carbono } \\
\left(\mathrm{mmol} \mathrm{g}^{-1}\right)\end{array}$ & $\begin{array}{c}\text { Hidrogênio } \\
\left(\mathrm{mmol} \mathrm{g}^{-1}\right)\end{array}$ & $\begin{array}{c}\text { Nitrogênio } \\
\left(\mathrm{mmol} \mathrm{g}^{-1}\right)\end{array}$ & $\begin{array}{c}\text { Cloreto } \\
\left(\mathrm{mmol} \mathrm{g}^{-1}\right)\end{array}$ \\
\hline Sílica Pura & 0,07 & 0,97 & 0,17 & - \\
Sil-IMI & 6,02 & 1,64 & 1,85 & 2,7 \\
Sil-IMI- $N\left(\mathrm{Tf}_{2}\right)^{-}$ & 6,79 & 0,93 & 1,18 & 0,0 \\
\hline${ }^{\mathrm{a}}=$ análise $\mathrm{CHN}^{-}{ }^{\mathrm{b}}=$ obtida por titulação potenciométrica com $\mathrm{AgNO}_{3} ;$ &
\end{tabular}

Com relação à análise de cloreto, os resultados mostraram que a funcionalização da sílica com o 1-metilimidazólio, apresentando 2,7 mmol de grupo orgânico por grama de 
sólido. A quantidade de $2,7 \mathrm{mmol} . \mathrm{g}^{-1}$ corresponde a íons cloretos trocáveis no material SilIMI (equivalente à quantidade de grupos imidazólio disponíveis no material). Após a reação de troca iônica do ânion cloreto pelo ânion $\mathrm{N}\left(\mathrm{Tf}_{2}\right)^{-}$não mais se detectou cloreto livre na titulação, indicando que todos foram substituídos pelo ânion $\mathrm{N}\left(\mathrm{Tf}_{2}\right)^{-}$.

\subsection{Espectroscopia Vibracional de Infravermelho com Transformada de Fourier (FTIR)}

A Figura 3 apresenta o espectro no infravermelho da sílica pura e funcionalizada. As bandas de vibração do ânion se manifestam em 571, 617 e $741 \mathrm{~cm}^{-1}$ correspondendo deformação angular simétrica no plano $\mathrm{CF}_{3}, \mathrm{SO}_{2}$ e $\mathrm{CF}_{3}$ respectivamente. A banda de vibração do cátion em $652 \mathrm{~cm}^{-1}$ refere-se às vibrações de deformação axial da metila do anel imidazólio. Em $812 \mathrm{~cm}^{-1}$ mostra a vibração da Si-C. Em 1230 e $1352 \mathrm{~cm}^{-1}$ correspondendo deformação axial simétrica do $\mathrm{CF}_{3}$ e deformação axial assimétrica $\mathrm{SO}_{2}$ respectivamente. A sílica aparece nas vibrações de 1191 e $1632 \mathrm{~cm}^{-1}$ correspondendo a $\mathrm{Si}-\mathrm{O}$ e absorção do esqueleto da sílica. Uma banda larga relativa à vibração das hidroxilas da água em 3000 a $3700 \mathrm{~cm}^{-1}$.

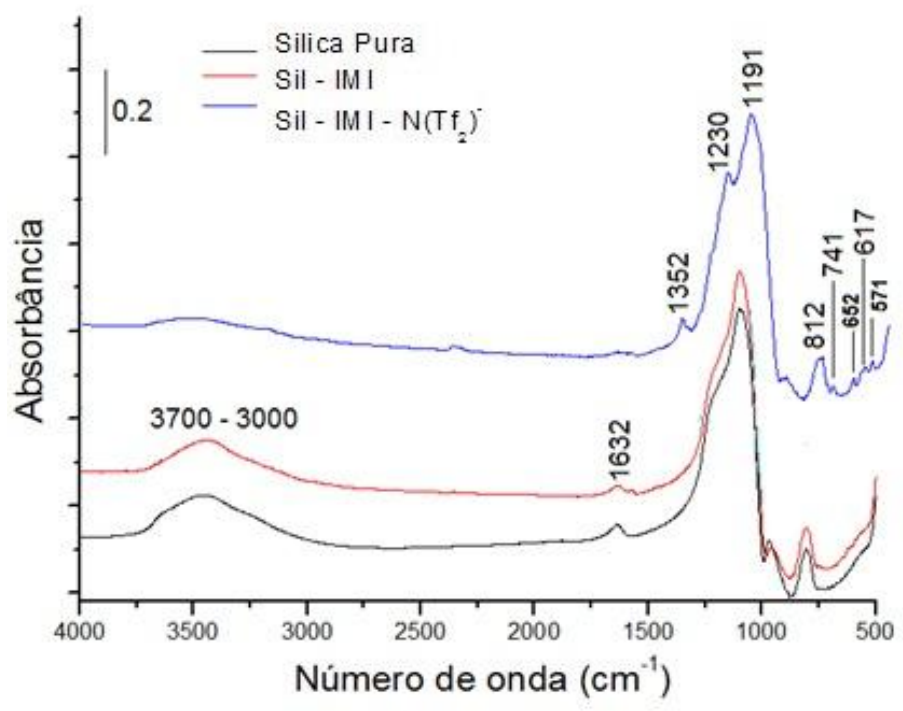

Figura 3. Espectro de infravermelho da sílica pura e funcionalizada em pastilha de $\mathrm{KBr}$.

\subsection{Capacidade de Adsorção}

A Figura 4 mostra a capacidade de adsorção versus o tempo de adsorção em diferentes concentrações iniciais de dibenzotiofeno sobre a Sil-IMI-N $\left(\mathrm{Tf}_{2}\right)^{-}$. O aumento da capacidade de adsorção indicou o aumento da quantidade de dibenzotiofeno adsorvido em função do tempo até que o equilíbrio de adsorção foi atingido. A concentração inicial proporciona uma força motriz importante para superar todas as resistências à transferência de massa do adsorvato entre a fase líquida e a fase sólida Alkan et al. (2007). Foi visto que a adsorção aumentou com o aumento da concentração inicial de dibenzotiofeno. A quantidade de dibenzotiofeno adsorvido no equilíbrio reflete a capacidade máxima de adsorção da Sil-IMI-N $\left(\mathrm{Tf}_{2}\right)^{-}$nas condições estudadas. A 
capacidade de adsorção de dibenzotiofeno em Sil-IMI-N $\left(\mathrm{Tf}_{2}\right)^{-}$no equilíbrio (qe) aumentou de 0,2 a $1,0 \mathrm{mg} / \mathrm{g}$ com o incremento da concentração inicial de 25 a $100 \mathrm{mg} / \mathrm{L}^{-1}$.

A Figura 4 apresenta o percentual de remoção do dibenzotiofeno sobre Sil-IMI-N $\left(\mathrm{Tf}_{2}\right)^{-}$ em função do tempo para diferentes concentrações iniciais. Aumentando-se a concentração inicial de 50 para $100 \mathrm{mg} / \mathrm{l}$, a percentagem de remoção do composto sulfurado diminuiu de 58 para $32 \%$. Isto aconteceu porque a quantidade de adsorvato aumentou, mas a quantidade de sítios de adsorção permaneceu a mesma, pois a massa de adsorvente foi constante e igual a $300 \mathrm{mg}$. Portanto, adicionar mais adsorvato não vai aumentar a adsorção, pois todos os sítios já foram ocupados.

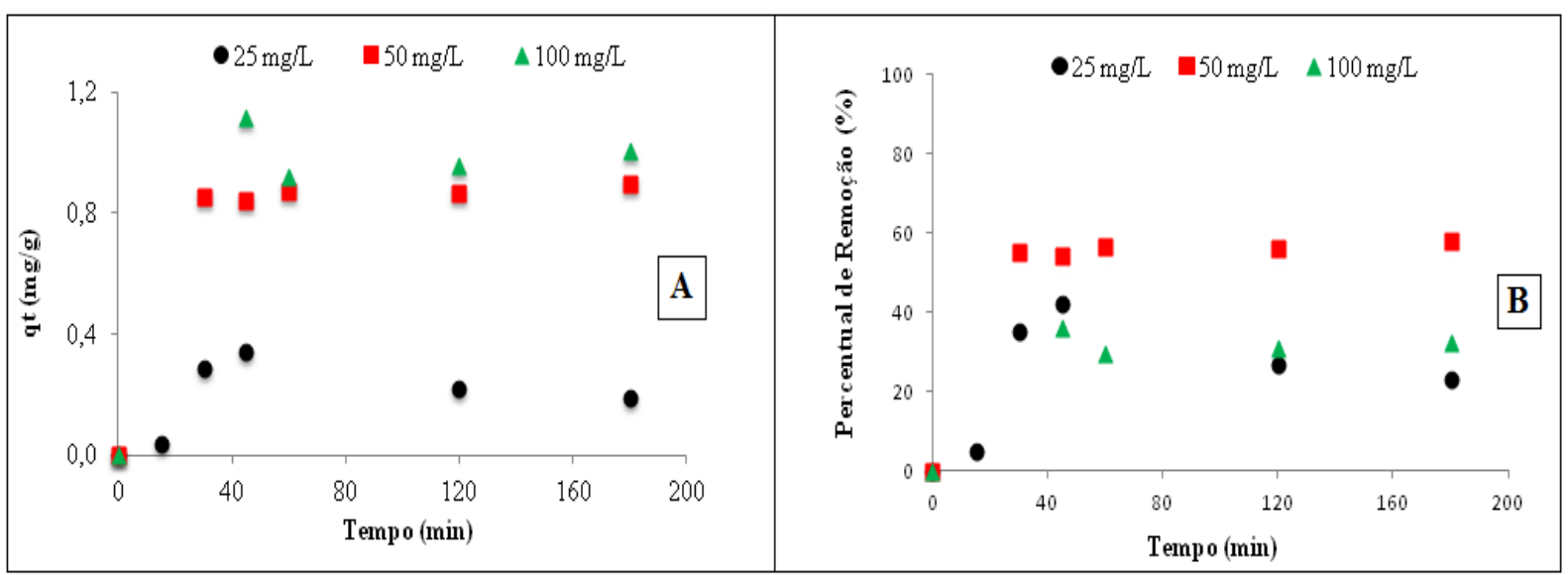

Figura 4 - (A) Capacidade de adsorção e (B) Percentual de remoção do dibenzotiofeno em SilIMI-N $\left(\mathrm{Tf}_{2}\right)^{-}$versus tempo de adsorção em diferentes concentrações iniciais. Condições: $\mathrm{T}=$ $40^{\circ} \mathrm{C}, \mathrm{m}_{\text {adsorvente }}=300 \mathrm{mg}$.

\section{CONCLUSÕES}

A combinação da sílica com material orgânico ionizado (líquido iônico, LI), levou o desenvolvimento de um novo material híbrido orgânico - inorgânico com capacidade de adsorver dibenzotiofeno em torno de $58 \%$.

As análises texturais confirmaram a mudança na estrutura da sílica, influenciando na área, volume e diâmetro de poros. O efeito da temperatura sobre o equilíbrio de adsorção do dibenzotiofeno em Sil-IMI-N $\left(\mathrm{Tf}_{2}\right)^{-}$mostrou que as interações acontecem por pontes de hidrogênio e aparentemente a estabilidade dessa ligação diminui com o aumento da temperatura entre 20 e $60^{\circ} \mathrm{C}$.

\section{REFERENCIAS}

ALKAN, M.; Özkan, D.; MEHMET, D. Adsorption kinetics and thermodynamics of an anionic dye onto sepiolite, Microporous and Mesoporous Materials, 101(3), p. 388-396, 2007. 
GREGG, S. J.; SING, K. S. W., Adsorption , Surface and Porosity. 2ed., Academic Press, London, 1982.

IRVINE, R. L. Process for desulfurizing gasoline and hydrocarbon feedstocks.Dissertação de Mestrado, United States, USA, 1998.

LOWELL, S.; SHIELDS, J. Powder surfacearea and porosity. 3ed. New York: John Wiley \& Sons, 1979.

MARÍN-ROSAS, C.; RAMÍREZ-VERDUZCO, L. F.; MURRIETA-GUEVARA, F. R.; HERNÁNDEZ-TAPIA, G.; RODRÍGUEZ-OTAL, L. M. Desulfurization of Low Sulfur Diesel by Adsorption Using Activated Carbon: Adsorption Isotherms, Industrial \& Engineering Chemistry Research, 49, p. 4372-4376, 2010.

STORCK, S; BRETINGER, H.; MAIER, W. F.Characterization of micro- and mesoporous solids by physisorption methods and pore-size analysis, Applied Catalysis A: General - 174, p. 137-146, 1998.

THOMAS, J. E. A. P.; TRIGGIA, A.A.; CORREIA, C. A.; VEROTTI, C.; XAVIER, J. A. D.; MACHADO, J. A. D.; GOUVÊA, P. C. V. M.; CARVALHO, R. S.;BARRAGAN, R. V. Fundamentos de Engenharia de Petróleo, 2 ed. Rio de Janeiro, Interciência, 2004. 